\title{
3D Simulation of Local Diesel-water Two Phases Flow in a Tube with Elbow
}

\author{
G.L. XU \& L.X. CAI* (corresponding author)
}

Petroleum Engineering Institute, Southwest Petroleum University, Chengdu, China

Oil \& Gas fire protection key laboratory of Sichuan province, Chengdu, China

\section{Z.L. WANG}

Petro China Oil \&Gas Pipeline Control Center, Beijing, China

C.L. FU

CNPC Offshore Engineering Company Limited, Qingdao, China

\begin{abstract}
Calculated local diesel-water two phases flow in a tube with elbow were compared with experimental data. The well-known volume of fluid (VOF) model combined with continuum surface tension (CSF) model and an interface geometric reconstruction method was used to simulate the flow phenomena by a computational fluid dynamics (CFD) approach. The simulated flow pattern, critical oil superficial velocity and water average velocity are in good agreement with the experiments, and reveal why severe internal corrosion occurs in some spots of pipelines. Hence, the water deposited in pipeline could be flushed out only when the oil flow rate exceeds the critical value.
\end{abstract}

KEYWORD: CFD; VOF; Local two-phase flow; Water displacement

\section{INSTRUCTIONS}

Products oil pipelines laid along the terrain are usually commissioned following water pressure test directly. Hence there are some residual water stuck in some lower spots particularly during the shutdown, which results in lower transportation efficiency and higher internal corrosion rate. Few literatures addressed the possibility of purging residual water from a $\mathrm{V}$-shaped pipe (Birvalski et al. 2014) [1] and U-shape pipe by spiral air flow and axial air flow (Horii et al. 1997[2], Shen et al. 2002[3]). This flow was defined as 'local two-phase flow' (Xu et al. 2015)[4] whose flow characteristics are far different from the traditional two phases flow. Flow phenomena of products oil (diesel)-water in the case of water initially trapped in a lower section and then sheared by flowing diesel into upward section were studied in this work by three dimensional CFD simulations.

In previous studies (Xu et al. 2011a, b) [5-6] several possible mechanisms for the onset of water displacement in hilly tube were considered and the corresponding critical (minimal) oil flow rates for the water displacement were evaluated. The predicted critical oil superficial velocity $\left(U_{\mathrm{os}}\right)$ were compared with the experimental data obtained from two steel hilly test loops with diameter (I.D.) of 27 $\mathrm{mm}$ and $41 \mathrm{~mm}$ using diesel and tap water as test fluids. The 'plug formation model' was verified to predict the flow interface profile and the critical $U_{\text {os }}$ well.
In the present work numerical calculation results for diesel-water two phases flow patterns in hilly tube were compared with the published experimental data (Xu et al. 2015)[4].

\section{MODELLING AND SIMULATIONS}

Multiphase flow processes may exhibit different flow regimes and flow patterns depending upon the operating conditions. Generally, there are three steps needed to be considered: definition of each phase, controlling equations and the modeling the multiphase flow (De Schepper et al. 2008)[7]. The transient flow numerical simulation in this work was conducted by a commercial CFD solver (FLUENT software).

Two immiscible phases were defined as diesel and water (i.e., the test fluids in experiments). The volume of fluid (VOF) model is utilized to deal with such a problem which involves an oil-water free interface (Hirt \& Nichols 1981)[8] The continuum surface tension (CSF) model which is applicable to flow phenomena influenced by interfacial tension (Brackbill et al. 1992)[9] is adopted to transform the interfacial tension into a source force.

\subsection{Geometric model}

The simulations are conducted by a hilly tube consisting of horizontal and upward inclined section with pipe diameter $50 \mathrm{~mm}$ and inclination angel $10^{\circ}$, $15^{\circ}, 20^{\circ}$, respectively. The geometrical model and 
coordinates are shown in Fig. 1, where the initial water distribution is set in a lower horizontal section. The unstructured quadrilateral grid is adopted for surface mesh generation while hybrid grid is adopted by cooper method for the body generation. The 3Dcomputional domain was divided into about $30 \times 10^{4}$ cells for tubes. Rigorous grid independence tests have been performed and then the grid strategies was chosen based on those tests.

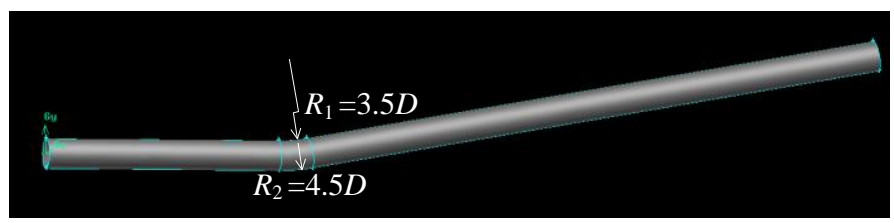

Fig. 1. Schematic description of the geometric model and coordinates used in the simulation.

$R_{1}, R_{2}$ are the radiuses of curvature at the elbow.

\subsection{Volume of Fluid (VOF) model}

VOF model was firstly brought about by Hirt \& Nichols (1981)[8] to track the free interface throughout the computational domain. A fluid volume fraction function (i.e., the ratio of the $k$ th fluid's volume fraction in the cell, denoted as $\alpha_{k}$ ) is defined, then the following three situations are possible:

- $\alpha_{k}=0$ : the cell does not contain the $k$ th phase;

- $\alpha_{k}=1$ : the cell is filled with the $k$ th phase;

- $0<\alpha_{k}<1$ : the cell contains the interface between the $k$ th phase and other phases.

In the VOF approach, a single set of conservation equations is shared by the phases. Ignoring the mass transfer between phases and the compressibility of phases, the mass and momentum conservation equations can be written as:

$\frac{\partial \rho}{\partial t}+\nabla \cdot(\rho \vec{U})=0$

$\frac{\partial(\rho \vec{U})}{\partial t}+\nabla \cdot(\rho \vec{U} \vec{U})=-\nabla P+\rho \vec{g}+\nabla \cdot \mu\left[\nabla\left(\vec{U}+\vec{U}^{T}\right)\right]+\vec{F}_{\mathrm{s}}$

where the superscript $\rightarrow$ represents a vector; $\rho, \mu$ denotes the density and viscosity depending upon the fluid volume fraction $(\alpha)$ shown in Eq. 3. Vector $F_{\mathrm{s}}$ represents the external volume source force solved by continuum surface force (CSF) model shown in Eq. 4.

$$
\rho=\alpha \rho_{\mathrm{w}}+(1-\alpha) \rho_{\mathrm{o}} ; \mu=\frac{\alpha \rho_{\mathrm{w}} \mu_{\mathrm{w}}+(1-\alpha) \rho_{\mathrm{o}} \mu_{\mathrm{o}}}{\alpha \rho_{\mathrm{w}}+(1-\alpha) \rho_{\mathrm{o}}}
$$

$\vec{F}_{\mathrm{s}}=2 \rho \sigma c \nabla \alpha /\left(\rho_{\mathrm{o}}+\rho_{\mathrm{w}}\right)$

where the subscript $\mathrm{w}$, o represents water and oil, respectively; $\alpha=$ fluid volume fraction; $c=$ curvature of the interface; $\sigma=$ interfacial tension, $\mathrm{N} / \mathrm{m}$.

Volume fraction $\alpha$ transport equation is written as:

$\frac{\partial \alpha}{\partial t}+\nabla \cdot(\alpha \vec{U})=0$
Because VOF function is a step function, hence conventional difference scheme cannot be adopted to discrete equations. Youngs interface geometric reconstruction (Geo-Reconstruction) method, (Youngs 1982)[10] is used to deal with the interface.

\subsection{Simulations and boundary conditions}

A pressure-based solver combined with an implicit approach is employed to simulate this transient flow phenomenon with a time step of $0.001 \mathrm{~s}$. The calculations are performed by combination of the PISO algorithm (Issa, 1986)[11] for pressurevelocity coupling, third-order MUSCL discretization scheme for momentum and Geo-Reconstruct scheme for volume fraction. Laminar or Realizable $k-\varepsilon$ turbulent model is adopted depending upon the Reynolds number (Re): laminar model for the cases of $\operatorname{Re}<2000$ while Realizable model for others cases. Gravity acceleration and contact angle are constants, $-9.81 \mathrm{~m} / \mathrm{s}^{2}$ and $120^{\circ}$, respectively. The physical properties for diesel and water were set as $858.1,998.0 \mathrm{~kg} / \mathrm{m}^{3}$ (density), 3.73, $1.0 \mathrm{mPa} \cdot \mathrm{s}$ (viscosity), respectively, while the interfacial tension is $14.6 \mathrm{mN} / \mathrm{m}$ (physical properties at $20^{\circ} \mathrm{C}$ ).

For all cases calculated, three boundaries are considered:

- Velocity condition at the inlet. Parabolic velocity profile and zero water fraction is employed for laminar incoming oil flow while a given fixed velocity and zero water fraction is used for turbulent oil flow.

- pressure condition at the outlet;

- stationary and no-slip tube wall.

Initial water is stationary in lower horizontal section of the tube for the water holdup of $0.1,0.2$, 0.3 and 0.4 .

\section{SIMULATION RESULTS AND DISCUSSIONS}

\subsection{Flow pattern}

In the experiments (Xu et al. 2015)[4] water was found to accumulate as an eccentric elongated water drop with a smooth or wavy interface in the elbow with a superficial velocity $\left(U_{\mathrm{os}}\right)$ less than a critical value. As $U_{\text {os }}$ exceeding the critical value, water was flushed into the upward section and move forward as a few smaller water drops/droplets and a chunk.

The simulation results for the different flow patterns can be found in Fig. 2 with the initial water holdup of 0.1 and the upward inclination of $20^{\circ}$. Diesel-water flow is found to be a local stratified flow with heavy water phase near the under wall as an eccentric elongated water drop or eccentric water chunks. Deposited water is found to be flushed and accumulate in the elbow under a slight shear from a low $U_{\text {os. }}$. As shown in Fig. 2a, interface is relative smooth when $U_{\text {os }}=0.13 \mathrm{~m} / \mathrm{s}$. Water will move 
forward with a thicker and shorter appearance under an increasing $U_{\text {os }}$. Interface downstream becomes wavy and even some of water is sheared away from water drop into smaller droplets flowing forward along the flowing diesel (as shown in Figs. 2b, c). This flow process is quite the same with the measured phenomenon (Xu et al. 2015)[4].

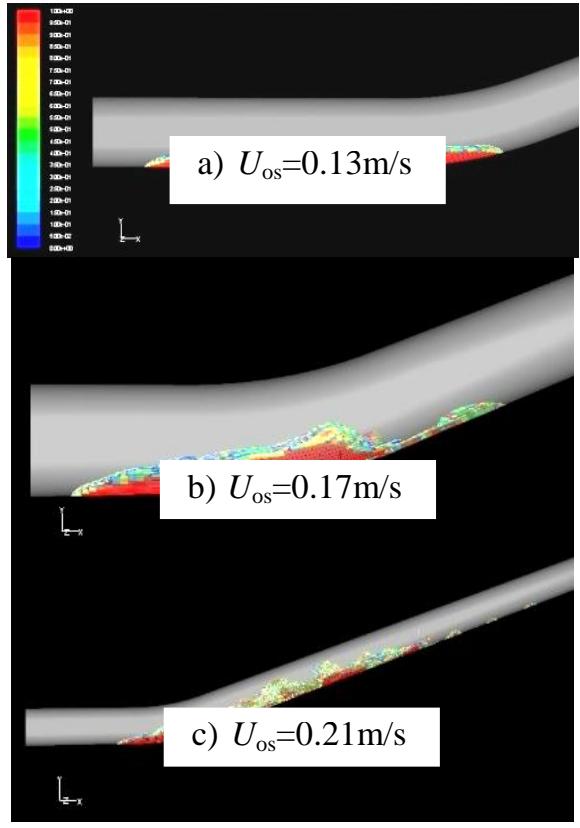

Fig. 2. Flow patterns in the system of deposited water flushed by flowing diesel with $\beta=20^{\circ}, \varepsilon=0.1$.

The minimal oil superficial velocity for all water entering the upward section with a positive average velocity is a key parameter to judge whether water could be withdrawn or not. Hence, this minimal $U_{\text {os }}$ is defined as $\left(U_{\mathrm{os}}\right)_{\mathrm{cr}}$. As $U_{\mathrm{os}}$ exceeding $\left(U_{\mathrm{os}}\right)_{\mathrm{cr}}$, entire water drop would enter the up-inclined section and move in a positive average velocity.

\subsection{The critical oil superficial velocity, $\left(U_{o s}\right)_{c r}$}

The simulated $\left(U_{\mathrm{os}}\right)_{\mathrm{cr}}$ under different inclination angles and initial water holdups compared with experimental results are shown in Table 1. The $\left(U_{\text {os }}\right)_{\text {cr }}$ increases as inclination angle increasing while is insignificantly affected by the water holdup. The simulation results are in a good agreement with the experiments with the largest deviation of $21.1 \%$.

Table 1. Comparison of the simulated $\left(U_{\mathrm{os}}\right)_{\mathrm{cr}}$ with experiments.

\begin{tabular}{|c|c|c|c|c|c|c|}
\hline \multirow{3}{*}{$\begin{array}{l}\text { Initial } \\
\text { water } \\
\text { holdup } \\
, \varepsilon\end{array}$} & \multicolumn{6}{|c|}{ Inclination angle, $\beta$} \\
\hline & \multicolumn{2}{|c|}{$10^{\circ}$} & \multicolumn{2}{|c|}{$15^{\circ}$} & \multicolumn{2}{|c|}{$20^{\circ}$} \\
\hline & $\begin{array}{c}\text { Measur } \\
\text { ed } \\
\left(U_{\mathrm{os}}\right)_{\mathrm{cr}}\end{array}$ & $\begin{array}{c}\text { Simulat } \\
\text { ed } \\
\left(U_{\text {os }}\right)_{\text {cr }}\end{array}$ & $\begin{array}{c}\text { Measur } \\
\text { ed } \\
\left(U_{\mathrm{os}}\right)_{\mathrm{cr}}\end{array}$ & $\begin{array}{c}\text { Simulat } \\
\text { ed } \\
\left(U_{\mathrm{os}}\right)_{\mathrm{cr}}\end{array}$ & $\begin{array}{c}\text { Measur } \\
\text { ed } \\
\left(U_{\mathrm{os}}\right)_{\mathrm{cr}}\end{array}$ & $\begin{array}{c}\text { Simulat } \\
\text { ed } \\
\left(U_{\mathrm{os}}\right)_{\mathrm{cr}}\end{array}$ \\
\hline 0.1 & 0.18 & 0.19 & 0.19 & 0.23 & 0.22 & 0.25 \\
\hline 0.2 & 0.18 & 0.20 & 0.20 & 0.24 & 0.23 & 0.24 \\
\hline 0.3 & 0.19 & 0.20 & 0.21 & 0.23 & 0.23 & 0.25 \\
\hline 0.4 & 0.19 & 0.20 & 0.20 & 0.23 & 0.23 & 0.25 \\
\hline
\end{tabular}

The $\left(U_{\text {os }}\right)_{\text {cr }}$ for the system with larger diameter were shown in Fig. 3 in the case of $\varepsilon=0.3, \beta=10^{\circ}$. The $\left(U_{\mathrm{os}}\right)_{\mathrm{cr}}$ was found to increase linearly as diameter increasing with the fitting equation of $\left(U_{\mathrm{os}}\right)_{\mathrm{cr}}=0.0041 D-0.014$. Take someone products oil pipeline transporting diesel with $D=500 \mathrm{~mm}$ and $\rho_{\mathrm{o}}$ $=800 \mathrm{~kg} / \mathrm{m}^{3}$ as an example, the $\left(U_{\mathrm{os}}\right)_{\mathrm{cr}}$ is $2.038 \mathrm{~m} / \mathrm{s}$ by substituting $D=500 \mathrm{~mm}$ into the fitting equation. Hence, the oil flow rate equals $970 \times 10^{4} \mathrm{t} / \mathrm{a}$ assuming the normal production days of 350 days per year. However the largest throughput is $350 \times$ $10^{4} \mathrm{t} / \mathrm{a}$ in the early commission and $800 \times 10^{4} \mathrm{t} / \mathrm{a}$ in present for that pipeline ignoring the production shutdown in its early life. Therefore, there should be some water hiding somewhere and cannot be displaced by flowing oil, which reveals the reason of severe internal corrosion and huge amount of corrosion products in pigging.

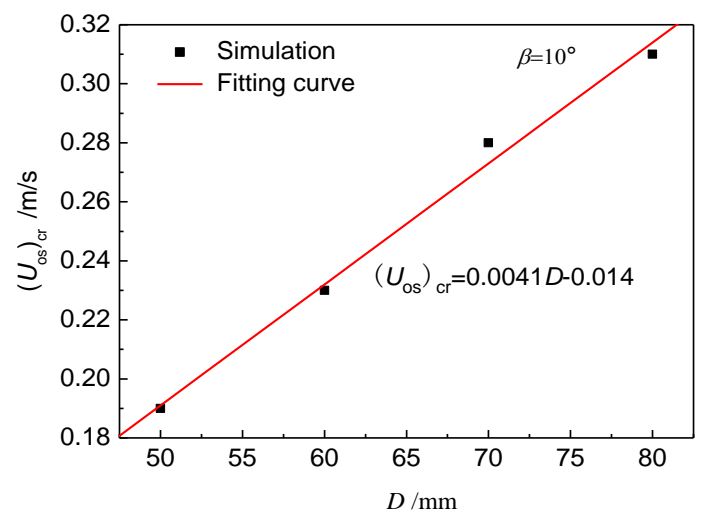

Fig. 3. Relationship of $\left(U_{\mathrm{os}}\right)_{\mathrm{cr}}$ vs. diameter with $\varepsilon=0.3, \beta=10^{\circ}$.

The effect of physical properties of oil fluid on the critical $U_{\text {os }}$ has also been carried out. The results are shown in Table 2 with the critical $U_{\text {os }}$ unit of $\mathrm{m} / \mathrm{s}$ by comparing diesel and gasoline. The $\left(U_{\mathrm{os}}\right)_{\mathrm{cr}}$ was found to decrease with increasing the oil viscosity and density (i.e., with lowering the density difference) under the conditions of constant initial water holdup.

Table 2. Effect of oil physical properties on the critical $U_{\text {os }}$.

\begin{tabular}{|c|c|c|c|}
\hline \multirow{2}{*}{ Oil name } & \multicolumn{3}{|c|}{ Inclination angle, $\beta$} \\
\cline { 2 - 4 } & $10^{\circ}$ & $15^{\circ}$ & $20^{\circ}$ \\
\hline Gasoline & 0.19 & 0.28 & 0.32 \\
\hline Diesel & 0.19 & 0.23 & 0.26 \\
\hline
\end{tabular}

\subsection{The average water velocity, $U_{w}$}

All the left-over water could be withdrawn only when $U_{\text {os }}$ is larger than the critical value. And then some water would backflow because of the vortex in turbulence flow. The average water velocity $\left(U_{\mathrm{w}}\right)$ is responsible for the distance moving forward in a certain time. Entire water with $U_{\mathrm{w}}>0$ will be flushed out during a long enough time without any interference. The simulated $U_{\mathrm{w}}$ versus $U_{\mathrm{os}}$ in the system with $D=50 \mathrm{~mm}$ is shown in Fig. 4 in which 
the solid line denotes the fitting curve of the simulations with equations: $U_{\mathrm{w}}=0.54 \cdot U_{\mathrm{os}}-0.12, U_{\mathrm{w}}=$ $0.47 \cdot U_{\mathrm{os}}-0.10, U_{\mathrm{w}}=0.29 \cdot U_{\mathrm{os}}-0.07$ corresponding to $\beta$ $=10^{\circ}, 15^{\circ}$ and $20^{\circ}$, respectively. $U_{\mathrm{w}}$ decreases with increasing inclination angel at the same $U_{\text {os. }}$. Hence, water purging is harder for a larger inclination angle. Water average velocity increases linearly as $U_{\text {os }}$ increasing, i.e., the relationship between $U_{\mathrm{w}}$ and $\cdot U_{\mathrm{os}}$ could be denoted by drift flow model (Xu et al. 2012)[12] meaning that there are velocity slip between the two phases. Simulation results are in a quite good agreement with the experimental results shown in Fig. 5.

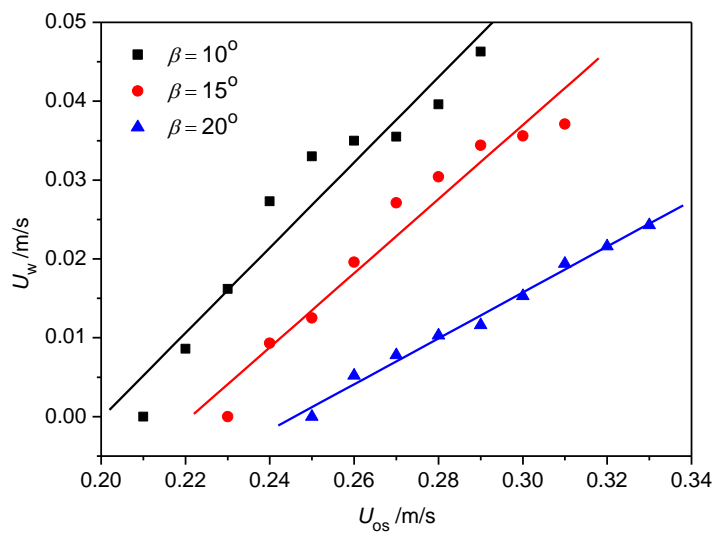

Fig. 4. Simulation relationship between $U_{\mathrm{w}}$ and $U_{\text {os }}$ in the system with $D=50 \mathrm{~mm}$.

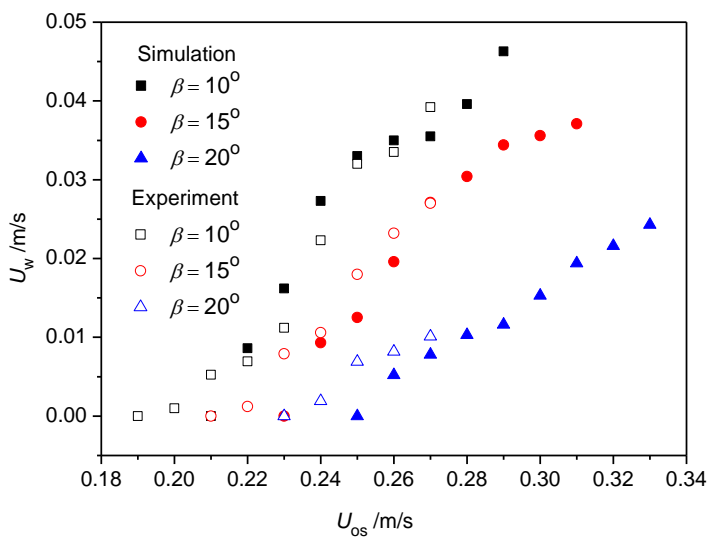

Fig. 5. Comparison of the simulated $U_{\mathrm{w}}$ with experiments in the system with $D=50 \mathrm{~mm}$.

\section{CONCLUSIONS}

All simulations give good agreement with the published experimental data. Water accumulates in the elbow as an eccentric elongated water drop with a smooth or wavy interface when sheared by a low $U_{\text {os }}$ while enters into the upward section as smaller water drops, droplets and chunks with a positive average velocity as $U_{\text {os }}$ exceeding the critical $U_{\text {os }}$. The critical $U_{\text {os }}$ increases linearly as pipe diameter increasing, decreases as inclination angle deceasing and oil viscosity and density increasing. Water average velocity increases linearly with increasing oil superficial velocity. Water purging is easier for a smaller inclination angle and higher oil velocity, density and viscosity. Hence water purging could be realized by enhancing the throughput.

\section{ACKNOWLEDGEMENT}

This work is financially supported by two funds, one is the Southwest Petroleum University fundamental research funds (natural science) (No. 2012XJZ002), the other is the special fund of China's central government for the development of local colleges and universities --- the project of national first-level discipline in Oil and Gas Engineering.

\section{REFERENCES}

[1] Birvalski M. K., G.B. \& Henkes R.A.W.M, 2014. Experiments and modelling of liquid accumulation in the low elbow of a gas/liquid pipeline. In D Carrington \& S Smith (Eds.), Proceedings of the 9th North American Conference on Multiphase Technology 2014, Cranfield, UK: BHR Group, 41-55.

[2] Horii K., Zhao Y.H., Tomita Y., 1997. High performance spiral air-flow apparatus for purging residual water in pipeline. In D P Telionis (Ed.) ASME Fluids Engineering Division Summer Meeting, Canada Vancouver: ASME, FEDSM 1997-3035, 1-6.

[3] Shen F., Yan Z.Y., Zhao Y.H., Horii K., 2002. Theoretical analysis of using airflow to purge residual water in an inclined pipe, Applied Mathematics and Mechanics 23, 694-702.

[4] Xu G.L., Zhang X., Cai L.X., et al., 2015. Experimental investigation on the flow characteristics of the local oilwater two phases flow system in hilly-terrain tube, Journal of Southwest Petroleum University (Science \& Technology), accepted.

[5] Xu G.L., Zhang G.Z., Brauner N., et al., 2011. Interface profile in oil-dragging-water pipeline system. Journal of China University of Petroleum (Science \& Technology) 35, 124-129.

[6] Xu G.L., Zhang G.Z., Liu G., et al., 2011. Trapped water displacement from low sections of oil pipelines. Int. J. Multiphase Flow 37, 1-11.

[7] De Schepper, Geraldine J.H., Guy B.M., 2008. CFD modeling of all gas-liquid and vapor-liquid flow regimes predicted by the Baker chart. Chemical Engineering Journal 138, 349-357.

[8] Hirt C.W., Nichols, B. D., 1981. Volume of fluid (VOF) method for the dynamics of free boundaries. $J$. Computational Physics 39, 201-225.

[9] Brackbill J.U., Kothe D. B., Zemach C., 1992. A continuum method for modeling surface tension. $J$. Computational Physics 100, 335-354.

[10] Youngs D. L. Time-dependent multi-material flow with large fluid distortion numerical method for fluid dynamics. New-York: Academic, 273-285.

[11] Issa R.L., 1986. Solution of the implicitly discretized fluid flow equations by operator splitting. J. Computational Physics, 62, 40-65.

[12] Xu G.L., Cai L.X., Ullmann A., et al., 2012. Trapped Water Flushed by Flowing Oil in Upward-inclined Oil Pipelines. in Proceedings of the Biennial international pipeline conference, 9th International Pipeline Conference, September 24-28,2012, Calgary, AB, Canada.637-647. 